\title{
Opera-Glass Hand in a Patient With Rheumatoid Arthritis
}

\author{
Yufeng Yin, PhD, Shuang Liu, MD, Hui Xiao, PhD, Mu Li, PhD, Jing Cai, PhD, \\ Jianhua Xu, MD, and Zongwen Shuai, MD
}

A

n 80-year-old woman presented with polyarticular tenderness and swelling that had begun 40 years earlier and been diagnosed as rheumatoid arthritis (RA) and exclusively diagnosed psoriatic arthritis and arthritis induced by other rheumatic diseases. Because of intolerance to chemical disease-modifying antirheumatic drugs (cDMARDs) including methotrexate, leflunomide, and hydroxychloroquine, and so on, she had been treated with low dose of corticosteroids and nonsteroidal anti-inflammatory drugs and then etanercept since 2007 until now.

Physical examination revealed that her fingers were significantly shortened, and finger skin was shiny, redundant, and "organ-like" wrinkled, which was consistent with opera-glass hand. There was malfunction of fingers as aberrant lateral activities were performed, and the fingers could be stretched or shortened arbitrarily, like a lorgnette (Fig. A, B). Moreover, fixed flexion deformity of bilateral elbows and lateral deviation of metatarsophalangeal joints were also found. Radiographs showed extensive phalangeal destruction and dissociation (Fig. C). Finally, the laboratory detection indicates that rheumatoid factor and anti-cyclic citrullinated peptide antibody were $203.9 \mathrm{IU} / \mathrm{mL}$ and $970 \mathrm{RU} / \mathrm{mL}$, respectively. Medical history indicates that this patient's deformity gradually progressed since 3 decades ago, even though disease activity was ameliorated after administration of methylprednisolone and celecoxib and supportive treatment.
The opera-glass hand, also known as telescoping fingers or main-en-lorgnette deformity, was first described in a 66-year-old woman with RA with distinctive hands deformities. ${ }^{1,2}$ Besides, these kinds of deformity could be developed in psoriatic arthritis ${ }^{3}$ and even systemic lupus erythematosus. ${ }^{4}$ As currently accepted, opera-glass hand is late stage of hand bone resorption and dislocation leading to shortening and instability. ${ }^{5}$ Opera-glass hands are extremely rare as early diagnosis and treatment of cDMARDs and biologic DMARDs are needed. However, patients with severe and refractory RA are at high risk of joint deformities resistant to both cDMARDs and biologic DMARDs.

\section{REFERENCES}

1. Nelson LS. The opera-glass hand in chronic arthritis. "La Main en Lorgnette" of Marie and Leri. J Bone Joint Surg. 1938;20:1045-1049.

2. Solomon WM, Stecher RM. Chronic absorptive arthritis or opera-glass hand: report of 8 cases. Ann Rheum Dis. 1950;9:209-220.

3. Ferreira MB, Sa N, Rocha SM et al. Opera glass hands: the phenotype of arthritis mutilans. BMJ Case Rep. 2013;2013.

4. Muniain M, Spilberg I. Opera-glass deformity and tendon rupture in a patient with systemic lupus erythematosus. Clin Rheumatol. 1985;4:335-339.

5. Nalebuff EA, Garrett J. Opera-glass hand in rheumatoid arthritis. J Hand Surg. 1976;1:210-220.
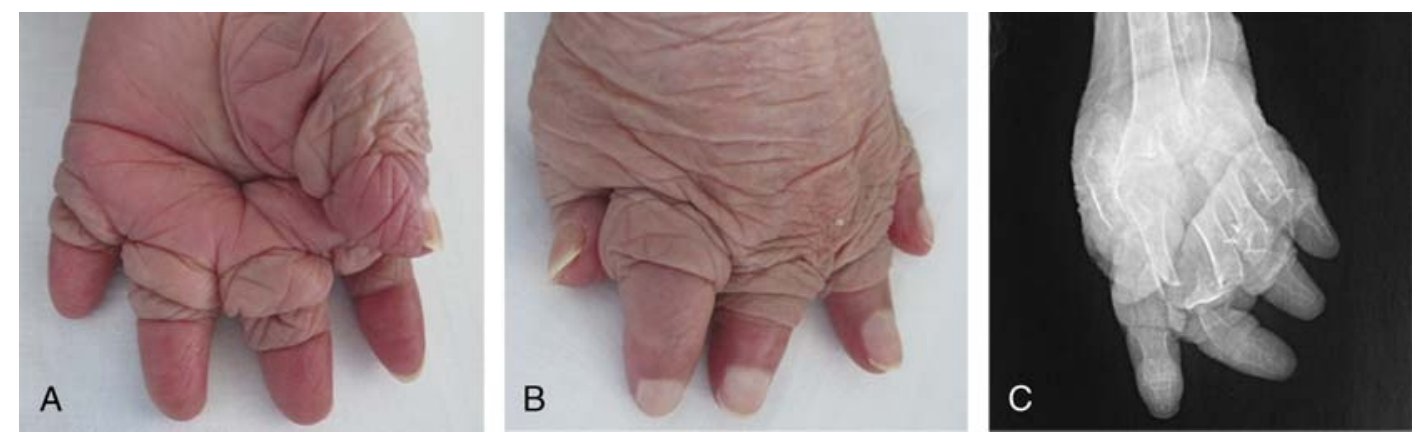

FIGURE. Color online-figures for A and B are available at http://www.jclinrheum.com.

From the Department of Rheumatology \& Immunology, First Affiliated Hospital of Anhui Medical University, Hefei, China.

The authors declare no conflict of interest.

Correspondence: Zongwen Shuai, MD, Department of Rheumatology \&

Immunology, First Affiliated Hospital of Anhui Medical University,

No. 218 Jixi Road, Shushan District, Hefei 230022, China.

E-mail: shuaizongwen@medmail.com.cn.

Copyright (C) 2016 Wolters Kluwer Health, Inc. All rights reserved. This is an open-access article distributed under the terms of the Creative Commons Attribution-Non Commercial-No Derivatives License 4.0 (CCBY-NC-ND), where it is permissible to download and share the work provided it is properly cited. The work cannot be changed in any way or used commercially. ISSN: $1076-1608$

DOI: $10.1097 /$ RHU.0000000000000388 